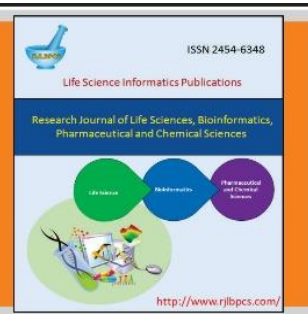

Life Science Informatics Publications

Research Journal of Life Sciences, Bioinformatics, Pharmaceutical and Chemical Sciences

Original Research Article

DOI: $10.26479 / 2019.0501 .08$

INFLUENCE OF SOIL MOISTURE ON ECTOMYCORRHIZAL FORMATION OF PRUNUS CERASOIDES BUCH. - HAM. EX D. DON

\title{
Seb $\mathbf{J}^{*}$, Ajungla $\mathbf{T}$
}

Department of Botany, Nagaland University, Lumami, Nagaland, India.

\begin{abstract}
The current study deals with the effect of soil moisture in ectomycorrhizal formation in the seedlings of Prunus cerasoides Buch. -Ham. Ex D.Don. inoculated with two native ectomycorrhizal fungi viz., Tricholoma imbricatum and Cantharellus cibarius, some seedlings were maintained as control. Soil samples were collected during different season. The study highlights the importance of soil moisture for optimum ectomycorrhizal formation which appears to have a positive impact on the increased growth of the seedlings. The study observes a significant improvement and increased in the growth of Prunus cerasoides seedlings between the mycorrhizal and non-mycorrhizal seedlings.
\end{abstract}

KEYWORDS: Cantharellus cibarius, growth parameters, soil moisture, Tricholoma imbricatum.

\section{Corresponding Author: Seb J*}

Department of Botany, Nagaland University, Lumami, Nagaland, India.

Email Address: jichuseb@gmail.com

\section{INTRODUCTION}

Mycorrhizal fungi are naturally occurring beneficial fungi that forms a symbiotic relationship with the plant. Mycorrhizal symbiosis is mostly used in reforestation programs to improve nutrition, growth and adaptation of plants in the soil. Ectomycorrhizal (ECM) symbiosis benefits forest trees in a number of ways in terms of uptake of water, enhancing soil nutrient mobilization and is an important contributor to the survival of seedlings in the forest production. The importance of ectomycorrhizal colonization to ecosystem processes has been well documented and artificial inoculation of ectomycorrhiza has been used in nursery seedlings. Most of the terrestrial ecosystems are dominated by plants that require association with the ectomycorrhizal fungi to achieve optimum

(C) 2019 Life Science Informatics Publication All rights reserved

Peer review under responsibility of Life Science Informatics Publications 
productivity. Ectomycorrhiza are structurally modified rootlets surrounded by mycobionts and the extramatrical hyphae and function as a link between the root system and soil. Ectomycorrhizal mycelia mainly function as primary organs for absorption of nutrients in many host plants [13].The study is an attempt to investigate the role of soil moisture in the formation of ectomycorrhiza to the roots of the seedlings and the growth performance of Prunus cerasoides inoculated with two native ectomycorrhizal fungi.

\section{MATERIALS AND METHODS}

The study was conducted in the field located at Nagaland University, Lumami under Zunheboto district, Nagaland, India. The seedlings of Prunus cerasoides were planted in experimental plot under field condition. Seedlings were planted at 1 meter equal distance apart and were allowed to establish with proper irrigation. Twenty seedlings were maintained for each different fungi and control. No fungal inoculum was added in the controlled seedlings. The fruiting bodies of the two native ectomycorrhizal fungi Cantharellus cibarius and Tricholoma imbricatum were collected from Lumami forest area and the young sporocarps were isolated for maintenance of pure culture in Modified Melin Norkan's medium (MMN) [15]. Fungal colonization after the inoculation was monitored under stereo microscope. Development of ectomycorrhiza was counted by counting dichotomy as one mycorrhiza. Percentage of mycorrhizal colonization/cm [23] was calculated as follows:

Total number of dichotomous branched rootlets

Ectomycorrhizal colonization $(\%)=\longrightarrow \times 100$

Total number of lateral rootlets

Rhizospheric soil moisture was determined by Gravimetric method [2].

\section{RESULTS AND DISCUSSION}

Ectomycorrhizal colonization was observed after the inoculation with Cantharellus cibarius and Tricholoma imbricatum. The percentage of ectomycorrhizal colonization was found to be higher in P. cerasoides inoculated with Tricholoma imbricatum (Fig 4). Roots of non inoculated (control) seedlings were also found to be colonized by ectomycorrhiza (Fig 4), as the experiment was performed in the field condition where air borne fungal spores may have colonized. During summer and autumn season the rhizospheric soil moisture of Tricholoma imbricatum inoculated seedlings was found higher, but at spring and winter season the rhizospheric soil moisture of Cantharellus cibarius inoculated seedlings was found higher (Fig 2). During the summer and autumn season, with high soil moisture (Fig 2) higher colonization percentage was observed but during the winter season, with low soil moisture low formation of ectomycorrhizal to the seedling roots was observed. Growth of the seedlings inoculated with the ectomycorrhizal fungi shown significant effect in all growth parameters in comparison with the control seedlings. Higher percentage of survival was observed

(C) 2019 Life Science Informatics Publication All rights reserved

Peer review under responsibility of Life Science Informatics Publications 

in the seedlings inoculated with ectomycorrhizal fungi.The symbiotic relationship between the fungal and host plant were found beneficial in the growth of the host species.

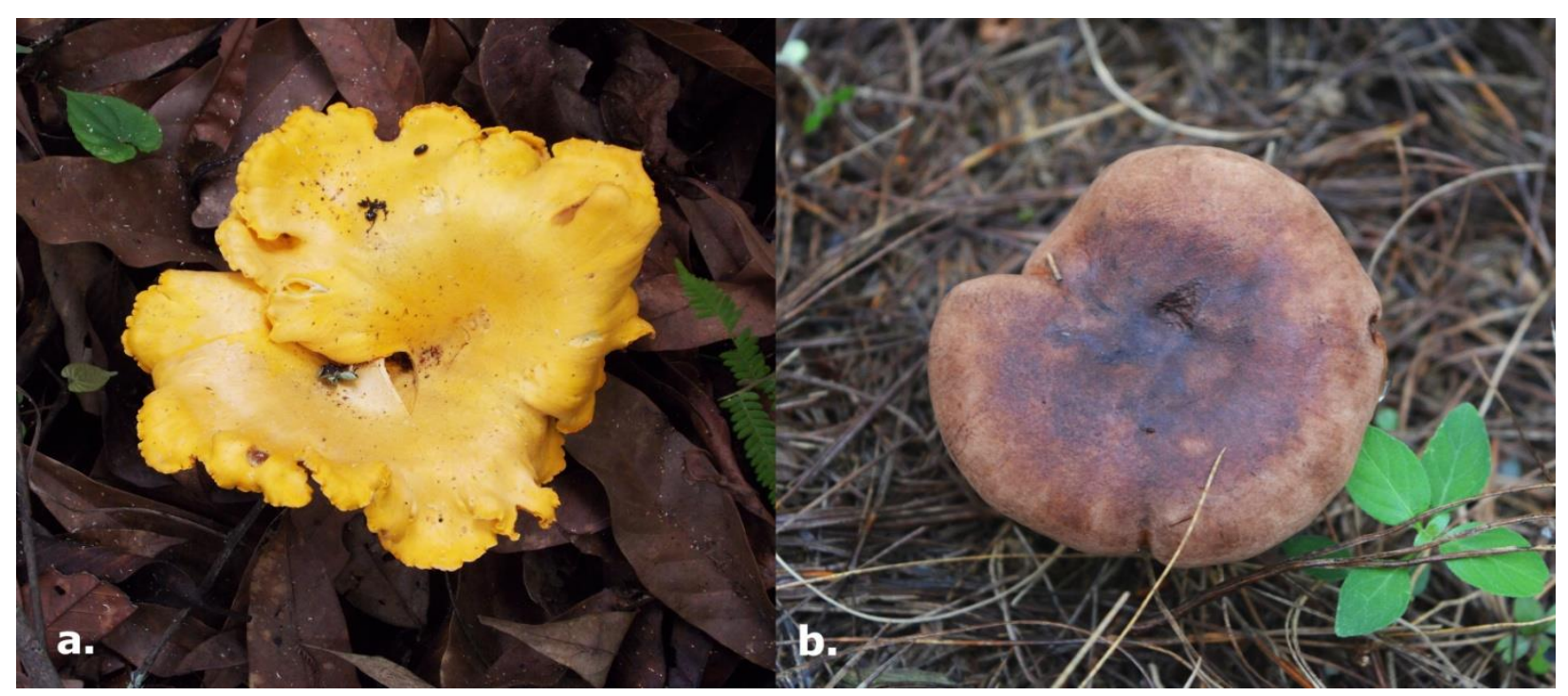

Fig 1: Ectomycorrhizal fungi (a). Cantharellus cibarius (Fr.) and (b). Tricholoma imbricatum (Fr.) P. Kumm.

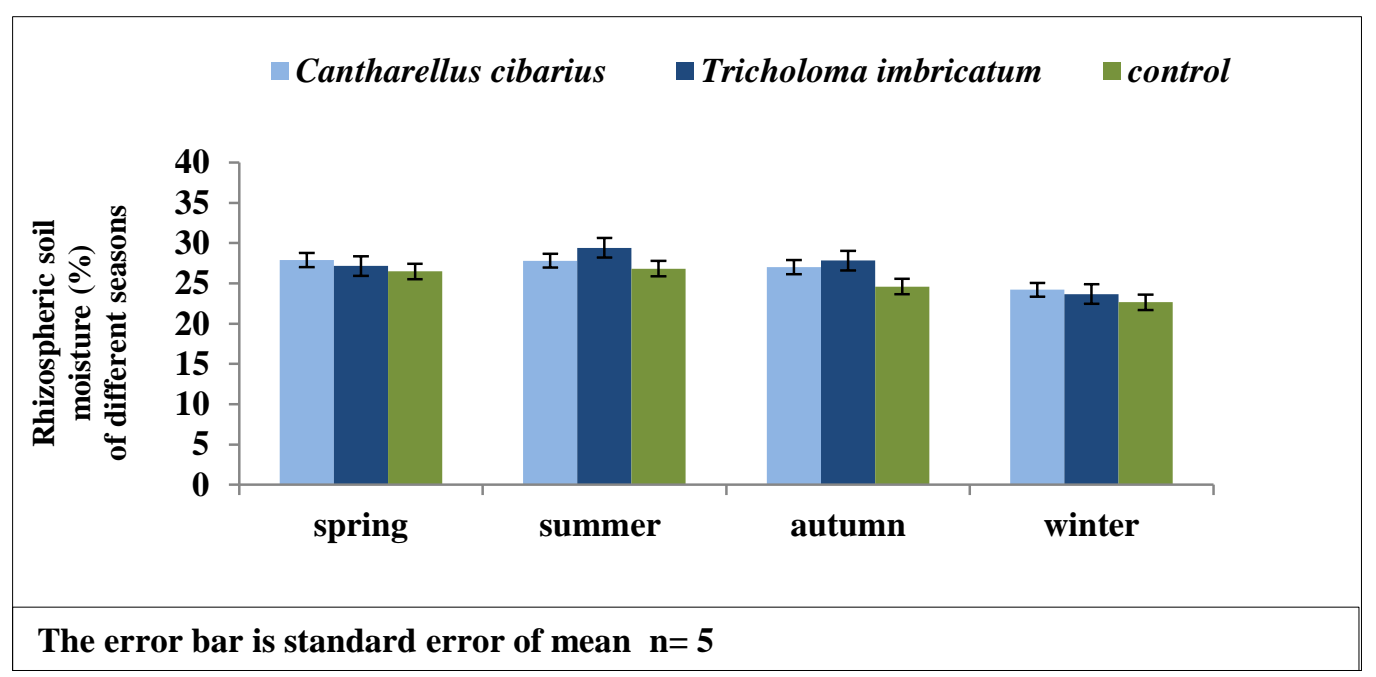

Fig 2: Rhizospheric soil moisture (\%) of $P$. cerasoides in different seasons

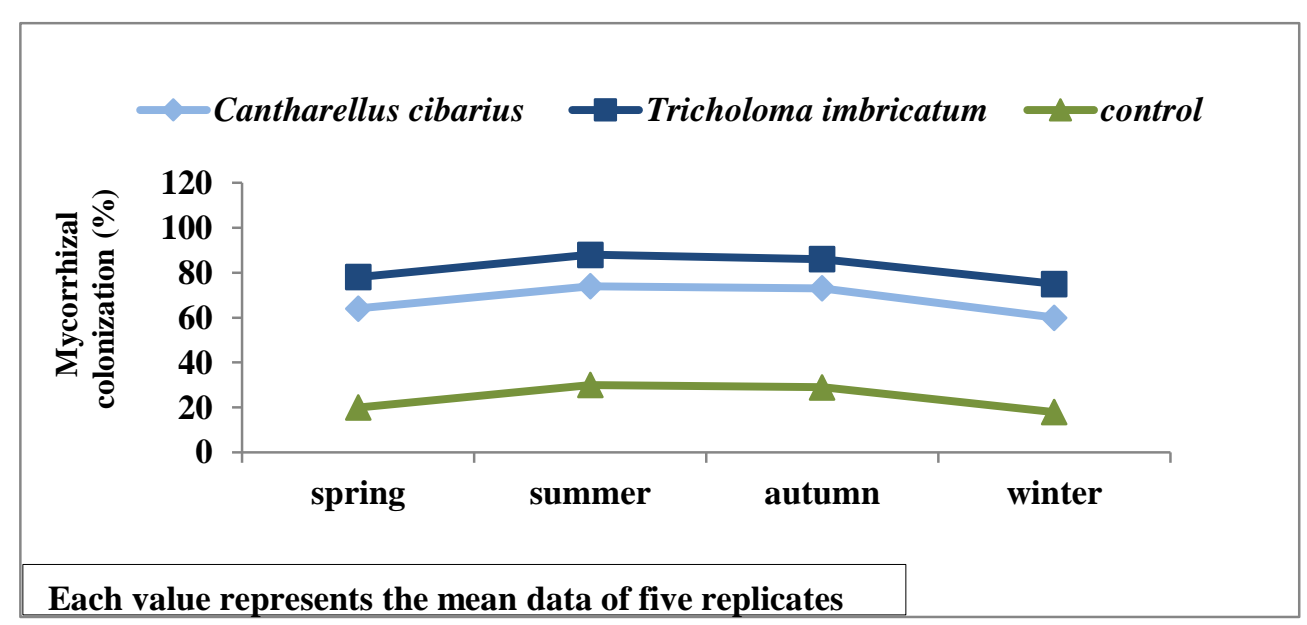

Fig 3: Percentage of ectomycorrhizal colonized roots of $P$. cerasoides in different seasons

(C) 2019 Life Science Informatics Publication All rights reserved Peer review under responsibility of Life Science Informatics Publications 2019 Jan - Feb RJLBPCS 5(1) Page No.77 


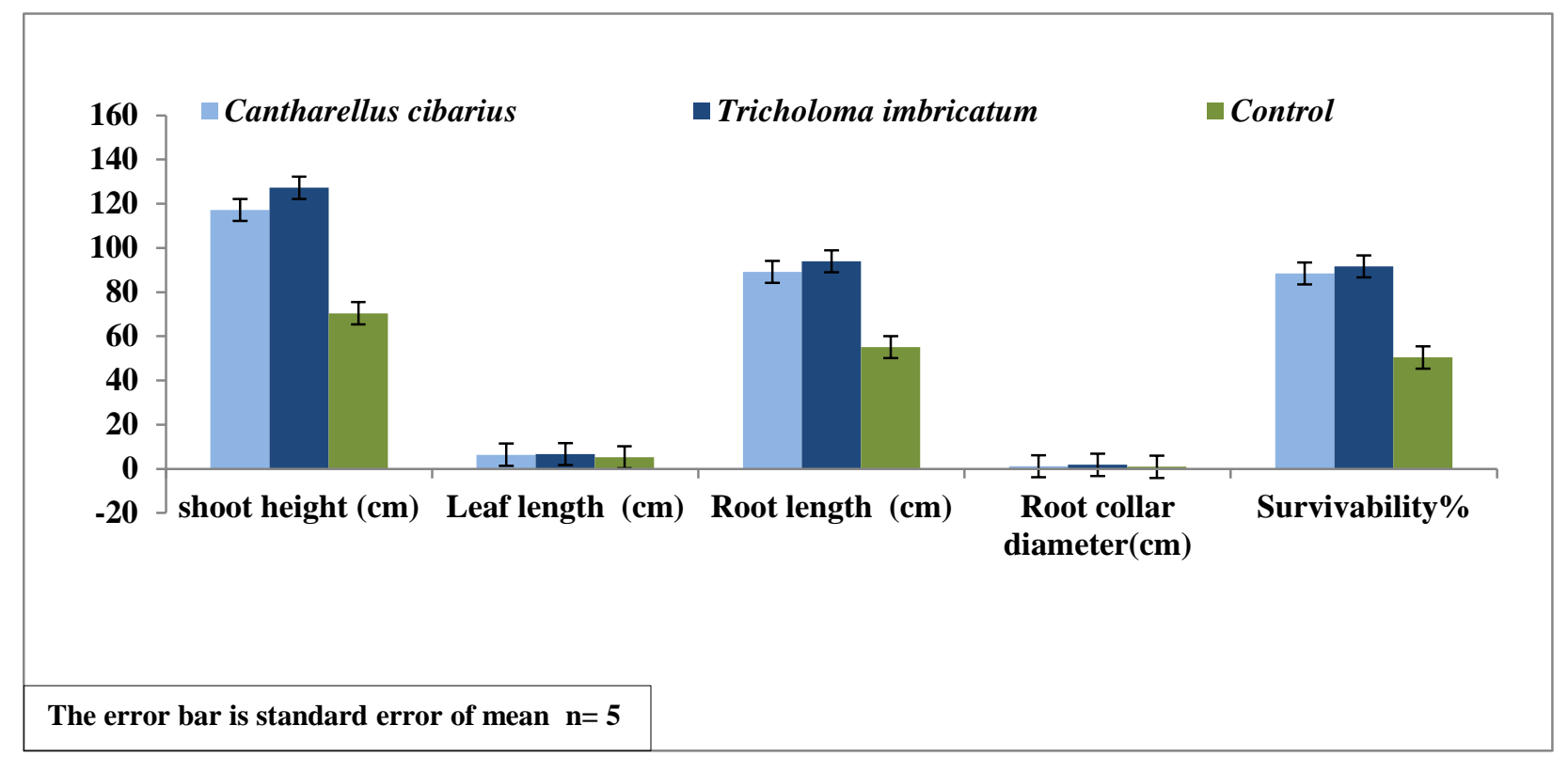

Fig 4: Growth and survivability of 1 year old $P$. cerasoides seedlings

\section{CONCLUSION}

A significant effect on the growth of inoculated seedlings can be attributed to increased absorptive surface area due to the extensive network of fungal mycelium resulting in increasing uptake of water and nutrients [6]. The result has demonstrated that the growth of the seedlings inoculated with the ectomycorrhizal fungi showed significant effect in all growth parameters in comparison with the control seedlings. Higher percentage of survival was observed in the seedlings inoculated with ectomycorrhizal fungi. Because of their extensive root system many tree species can survive well even in poor soil condition. In this study the symbiosis between the fungal and host plant were found beneficial in the growth of the host species. Thus, selection of suitable fungal symbiont for mycorrhizal inoculation is an important strategy. There is a need to conduct such studies under field conditions in order to prove usefulness of such technique in forest vegetation programmes.

\section{ACKNOWLEDGEMENT}

The author Jichule Seb is thankful to the University Grant Commission, Govt. of India, New Delhi, for financial help through UGC-BSR fellowship for the research work.

\section{CONFLICT OF INTEREST}

Authors declare that they have no conflict of interest.

\section{REFERENCES}

1. Ajungla T, Imliyanger Tzudir. Effects of ectomycorrhizal fungi on the growth performance of Pinus patula (Schiede ex Schlecht. \& Cham).Environ.Biol. Conservn. 2010; 15: 29-31.

2. Allen SE, Grinshaw HM, Parkinson JA, Quarmby C. Chemical Analysis of Ecological Material. Blackwell Scientific Publications, Oxford. 1974; 1- 565.

3. Aquino MT, Plassard C. Dynamics of ectomycorrhizal mycelial growth and P transfer to the host plant in response to low and high soil P availability. FEMS Microbial Eco. 2004; 48: 149-

(C) 2019 Life Science Informatics Publication All rights reserved Peer review under responsibility of Life Science Informatics Publications 

156.

4. BougherNL, Malajczuk N. Effects of high soil moisture on formation of ectomycorrhizas and growth of Karri (Eucalyptus diversicolor) seedlings inoculated with Descolea maculate, Pisolithus tinctorius and Laccaria laccata. New Phytol.1990; 114:87-91.

5. Cairney JWG. Basidiomycete mycelia in forest soils: dimensions, dynamics and roles in nutrient distribution. Mycological Research. 2005; 109: 7-20.

6. Colinas C, Molina R, Trappe, Perry D. Ectomycorrhizas and rhizosphere microorganisms of seedlings of Pseudotsuga menziesii (mirb) Franco planted on a degraded site and inoculated with forest soil pretreated with selective biocides. New Phytol. 1994; 127:529-537.

7. Duddridge JA, Malibari A, Read DJ. Structure and function of mycorrhizal rhizomorphs with special reference to their role in water transport. Nature. 1980; 287:834-836.

8. Fries Nils. Germination of Spores of Cantharellus Cibarius. Mycologia. 1979; 216-219.

9. Fortin JA, Piche Y, Lalonde M. Technique for the observation of early morphological changes during ectomycorrhiza formation. Can J Bot. 1980;58:361-365.

10. Gilmore AE. The influence of endotrophic mycorrhizae on the growth of peach seedlings. Soc. Hort. Sci. 1971; 96: 35-38.

11. Harley JL, Smith SE (Ed.) . Mycorrhizal Symbiosis. Academic Press, London. 1983; 483.

12. Kennedy PG, Peay KG . Different soil moisture conditions change the outcome of the ectomycorrhizal symbiosis between Rhizopogon sp. and Pinus muricata. Plant Soil. 2007; 291:155- 165.

13. Leake JR, Johnson D, Donnelly DP, Muckle GE, Boddy L, Read DJ. Networks of power and influence: the role of mycorrhizal mycelium in controlling plant communities and agroecosystem functioning. Canadian J of Bot. 2004; 82: 1016-1045.

14. Lodge DJ. The Influence of soil moisture and flooding in formation of VA; endo and ectomycorrhizae in Populus and Salix.Plant Soil. 1989; 117:243- 253.

15. Marx DH. The influence of ectotrophic mycorrhizal fungi on the resistance of pine roots to pathogenic infections. I. Antagonism of mycorrhizal fungi to root pathogenic fungi and soil bacteria. Phytopathology. 1969; 59(2):153-163.

16. Marx, D.H. Ectomycorrhizal fungus inoculation. In: Mikola P (edt.) A tool for Improving Forestation Practices. Mycorrhiza Res. Oxf. Univ. Press. 1980;13-17.

17. Marx DH, Bryan WC, Davey CB. Influence of temperature on aseptic symthesis of ectomycorrhizae by Thelephora terrestris and Pisolithus tinctorius on loblolly pine. 1970; For. Sci. 16: 424-431.

18. Melin E. Physiology of mycorrhizal relations in plants. Annuals Review of Plant Physio. 1953; 4: 325-346.

(C) 2019 Life Science Informatics Publication All rights reserved Peer review under responsibility of Life Science Informatics Publications 
19. Mexal J, Reid CPP. The growth of selected mycorrhizal fungi in response to induced water stress. Canadian J of Bot. 1973; 5: 1579-1588.

20. Morte A, DiazGR, AlarconJJP, Sanchez-BlancoMJ.Growth and water relations in mycorrhizal and nonmycorrhizal Pinus halepensis plants in response to drought. Physiol. Plant.2001; 44: 263-267.

21. Parke JL, Linderman RG, Black CH. The role of ectomycorhizas in drought tolerance of Douglas-fir seedlings. New Phytol. 1983; 95: 83-95.

22. Rapparini F, Baraldi R, Bertazza B. Growth and carbohydrate status of Prunus communis L. plantlets inoculated with Glomus sp. Agronomie. 1996; 16: 653-661.

23. Sharma G D. Ecological Studies on Ectomycorrhizae of pine (Pinus kesiya),Ph.D.Thesis, NEHU, Shillong. 1981.

24. Singh A, Lakhanpal TN in Dargan JS, Atri NS, Dhingra GS (Eds.). The fungi diversity conservation in India, Bishen Shingh Mahendra Pal Singh, Dehradun, India. 2005; 213-240.

25. Slankis V. Soil factors influencing formation of mycorrhizae. Annual Review of Phytopathol.1974;12: 437-457.

26. Smith SE, D Read. Mycorrhizal symbiosis. Elsevier Acad. Press. 2008; 815.

27. Swaty RL, Gehring CA, Van Ert M, Theimer TC, Keim P, Whitham TG. Temporal variation in temperature and rainfall differentially affects ectomycorrhizal colonization at two contrasting site. New Phytol.1998; 139: 733-739.

28. Swierczynski S, Stachowiak A. The influence of mycorrhizal fungi on the growth and yielding of plum and sour cherry trees. J of Fruit\& Ornamental Plant Res. 2010;18: 71-77.

29. Sylvia DM. Mycorrhizal Symbiosis, in Principles and application of Soil Microiology. 1999; 110.

30. Theodorou C. Soil moisture and the mycorrhizal association of Pinus radiata D. Don. Soil Bio \&Biochem.1978; 10: 33-37.

31. Worley JE, Hacskaylo E. Effect of available soil moisture on the mycorrhizal association of Virginia Pine. Forest Sc. 1959; 5: 267-268.

(C) 2019 Life Science Informatics Publication All rights reserved Peer review under responsibility of Life Science Informatics Publications 